\title{
Optimism and Its Impact on Mental and Physical Well-Being
}

\author{
Ciro Conversano ${ }^{1, \dagger, *}$, Alessandro Rotondo ${ }^{2, \dagger, *}$, Elena Lensi ${ }^{1}$, Olivia Della Vista ${ }^{1}$, Francesca \\ Arpone $^{1}$ and Mario Antonio Reda ${ }^{1}$
}

${ }^{1}$ Istituto di Scienze del Comportamento Università degli Studi di Siena, Policlinico Le Scotte viale Bracci-53100 Siena,
Italy, ${ }^{2}$ Azienda Ospedaliero Universitaria Pisana, Pisa, via Roma $67-56126$ Pisa, Italy

\begin{abstract}
Many studies have been carried out about the effectiveness of optimism as a psychological phenomenon, leading to various theoretical formulations of the same concept, conceptualized as "disposition", "attributional style", "cognitive bias", or "shared illusion". This overview is an attempt to explore the "optimism" concept and its relations with mental health, physical health, coping, quality of life and adaptation of purpose, health lifestyle and risk perception.

Positive and negative expectations regarding the future are important for understanding the vulnerability to mental disorders, in particular mood and anxiety disorders, as well as to physical illness. A significant positive relation emerges between optimism and coping strategies focused on social support and emphasis on positive aspects of stressful situations. Through employment of specific coping strategies, optimism exerts an indirect influence also on the quality of life. There is evidence that optimistic people present a higher quality of life compared to those with low levels of optimism or even pessimists. Optimism may significantly influence mental and physical well-being by the promotion of a healthy lifestyle as well as by adaptive behaviours and cognitive responses, associated with greater flexibility, problem-solving capacity and a more efficient elaboration of negative information.
\end{abstract}

Keywords: Optimism, Mental health, Physical health, Coping, Quality of life, Adaptation of purpose, Health lifestyle, Risk perception.

\section{INTRODUCTION}

As it is commonly understood, the term 'optimism' embraces two closely correlated concepts: the first is the inclination to hope, while the second more generally refers to the tendency to believe that we live in "the best of all possible worlds", as coined by the German philosopher Gottfried Wilhelm Leibniz in his famous theodicy, ridiculed in Voltaire's Candide.

Over the last few years, a significant body of research has been carried out about the effectiveness of optimism as a psychological phenomenon, leading to various theoretical formulations of the same concept, understood as "disposition", "attributional style", "cognitive bias", or "shared illusion".

Scheier and Carver [1] theorized the "disposition" towards optimism in their studies, called "dispositional optimism", considering it a trait of an equilibrated personality, in time and in various situations, that influences the way in which individuals come to terms with present, past and future events in life. Optimistic individuals are positive about events in daily life. In the research carried out regarding this perspective, positive correlations have been found between optimism and physical/mental well-being. Optimistic subjects tend to have more frequently protective attitudes, are more resilient to stress and are inclined to use more appropriate coping strategies.

*Address correspondence to these authors at the Istituto Di Scienze Del Comportamento, Viale Bracci, 16, 53100 Siena, Italy; Tel: +39 338 2694718; Fax: +39 0577 233215; E-mail: psicologiaapplicata@ gmail.com

${ }^{\dagger}$ These authors contributed equally to this work.
In open contrast, studies carried out by Peterson and Seligman [2], that were prevalently directed towards the understanding of the psychological bases of pessimism, lead to conception of its opposite, optimism, as an "attributional style", characterized by the tendency to believe that negative events are inconstant (the negative event will not repeat itself), external (I am not responsible for the event) and specific (the event is "specific", self-limiting and will not influence any other activities of mine and my life). Optimists believe that positive events are more stable and frequent than negative ones. They think that they can avoid problems in daily life and prevent them from happening, and therefore they cope with stressful situations more successfully than pessimists $[3,4]$.

Referring to the viewpoint of Social Cognition, a third perspective sustains that optimism is the consequence of a cognitive underestimation of risk, in other words, a "bias" for the Self. This bias reflects the optimist's conviction that positive events are more likely to occur to him/herself while negative events prevalently affect others. Weinstein $[5,6]$ defined this phenomenon "unrealistic optimism". The optimistic bias is not a personality trait like dispositional optimism [1] but rather a systematic cognitive distortion of the consideration of one's own probability of encountering negative events. The optimistic bias has been defined as the result of the joint efforts of two mechanisms. The first of these is related to cognitive factors such as lack of information and poor critical insight of one's own cognitive skills. The second mechanism has a motivational nature, closely tied to defending one's self-esteem and to defensive negation. 
This overiew is an attempt to explore optimism concept and its relations with mental health, physical health, coping, quality of life and adaptation of purpose, health lifestyle and risk perception.

\section{OPTIMISM AND MENTAL HEALTH}

Positive and negative expectations regarding the future are important for understanding the vulnerability to mental disorders, in particular mood disorders. Recent studies have found an inverse correlation between optimism and depressive symptoms $[7,8]$, and also between optimism and suicidal ideation [9]. As such, optimism seems to have an important moderating role in the association between feelings of loss of hope and suicidal ideation [10]. In relation to this, Van der Velden et al. [11] have recently studied the association between 'dispositional optimism' and depression in victims of a natural disaster. The results of this research show that compared to optimists, pessimists nurtured little hope for the future and were more at risk for depressive and anxiety disorders, with subsequent impairment of social functioning and quality of life. The role of optimism in the quality of life has also been investigated in depressive disorders emerging in patients suffering from somatic pathologies, (such as acute coronary syndrome, for instance) in which a significant inverse correlation was found between dispositional optimism and level of satisfaction in life on one hand and depressive symptoms emerging after the cardiovascular event on the other hand [12].

Giltay et al. [13] raised the question of using psychotherapy to promote an optimistic disposition in pessimistic subjects, thus developing an efficient strategy to fight depression. Evidence regarding this subject has emerged also from studies carried out on victims of catastrophic events such as natural disasters. In fact, it has been observed that even one single session of cognitive-behavioural therapy, targeted at enhancing the sense of control and coping with incapacitating disturbances that ensue after a natural disaster, may contribute to improving the well-being of the individual [14]. A brief intervention of this type, focused on recuperating an active coping strategy and regaining control, may be significant for 'pessimistic' victims, considering that they are more inclined to avoid problems and "give up", instead of trying to regain control of their lives [13].

\section{OPTIMISM AND PHYSICAL HEALTH}

Despite the small number of studies published on this matter, the relation between physical health and optimism is as important as that between optimism and mental health described above. Many studies have found that optimism is correlated with better physical well-being compared to pessimism. Moreover, in contrast with optimism, pessimism is correlated with excessive somatic complaints [15]. In a study on a population of elderly subjects of both sexes, aged between 65-85 years, Giltay et al. [16] noted that dispositional optimism predicted less probability of mortality in general and of cardiovascular mortality in particular. These data have been confirmed in a subsequent longitudinal study on a population of males aged between $64-84$ years in which an inverse correlation was reported between dispositional optimism and the risk of cardiovascular death [13]. Matthews et al. [17] observed that in the three years following the meno- pause, carotid atherosclerosis tended to progress more slowly in optimistic women compared to their pessimistic peers. In reference to oncological patients, Schulz et al. [18] noted that high scores on the pessimism items of the LOT (a measure of dispositional optimism) [1] significantly predicted premature death in young patients with breast cancer. Among patients with neck or head cancer, optimists manifested significantly greater survival a year after diagnosis when compared to pessimists [19]. In a recent study, Ironson et al. [20] showed how dispositional optimism, less avoidant coping strategies and lower level of depression positively influence progression of the illness in patients suffering from AIDS.

Although optimism is commonly believed to be a protective factor with regard to well-being and physical and psychical health [1] some research has suggested that this is not always the case. Schofield et al. [21] found that optimism did not predict lower mortality rates among lung cancer patients. Also studies concerning the immune system turned out contrasting results. Tomakowsky et al. [22] investigated the correlation between the "dispositional" optimism [1] and the "attributional" optimism [2,4] mentioned earlier, with the clinical and immune condition of subject affected with AIDS. The results of their research indicated that both types of optimism were associated with an improvement of the symptomatology of AIDS. Nevertheless, in the long term, high levels of optimism, in particular, of the attributional type, were associated with a significant impairment of the immune defence system. Milam et al. [23], on the other hand, found that high levels of optimism do not confer any clinical improvement to AIDS patients, although moderate levels were found to be associated with more efficacious immune systems. Segerstrom [24, 25] examined two hypotheses that may explain these results: the disappointment hypothesis, according to which persistent and uncontrollable stressors reduce the positive expectations that are typical of optimists and thus consequently control over the stress factors, leading to decrease in immune defence. The other is the engagement hypothesis theorizing that more optimistic individuals are more easily drawn to trying to resolve a problem while pessimists tend to let the matter drop, thus ending up more exposed to stress. As such, in cases of severe illnesses like AIDS, when associated with the elevated levels of cortisol and adrenalin that typically present when faced with stress, optimism may actually determine a decrease in the defence mechanisms of the immune system.

\section{OPTIMISM AND COPING}

Coping refers to those mechanisms and mental processes enacted by the individual as an adaptive response to reduce the stress deriving from a threatening situation, as defined by Lazarus and Opton [26].

From the early studies of Scheier $e t$ al. [27], a significant positive relation emerged between optimism and different aspects of life, such as coping strategies focalized on the problem, looking for social support and emphasis of the positive aspects of the stressful situation.

Despite a certain amount of dissent, other researchers confirmed the first results. Dispositional optimism was found to be positively correlated with those coping strategies ide- 
ated to eliminate, reduce or manage the stressors and negatively correlated with those employed to ignore, avoid or distance oneself from stressors and emotions [28]. Moreover, the choice of the coping strategy shows to be constant over the course of time [29]. Low levels of dispositional optimism were observed in students who were particularly vulnerable to the normal difficulties encountered in scholastic environments and who developed intolerance or even hostility towards the school [30]. Also in the work environment a positive association was observed between optimism and performance, mediated by the positive influence that optimism has on coping strategies [31]. Many studies have confirmed that optimists tend to use coping strategies that focalize on the problem more frequently compared to pessimists. When these strategies cannot be enacted, optimists resort to adaptive strategies that focalize on the emotions, for example, acceptance, humour and positive re-assessment of the situation [27, 32-34].

Through employment of specific coping strategies, optimism exerts an indirect influence also on the quality of life. In a sample of women with breast cancer Schou et al. [35] found that optimistic women presented coping strategies characterized by acceptance of the situation, emphasis of the positive aspects and attempts to alleviate their condition with a sense of humour, showing evident positive results on their quality of life. In contrast, the pessimistic women reacted with sentiments of impotence and loss of hope which significantly worsened their quality of life.

\section{OPTIMISM, QUALITY of LIFE AND ADAPTATION OF PURPOSE}

Quality of life refers to life conditions of an individual (health, wealth, social conditions) and satisfaction of personal desires, measured on a scale of personal values [36]. As such, we are dealing with a multidimensional construct that integrates objective and subjective indicators, a wide range of varying contexts of life and individual values.

Wrosch and Scheier [34] evidenced two variables capable of influencing quality of life: optimism and adaptation of purpose. Both in fact exert a fundamental role in adaptive management of critical circumstances in life and of goals to reach. There is evidence that optimistic people present a higher quality of life compared to those with low levels of optimism or even pessimists [37, 38]. It has been demonstrated that in the presence of severe pathological conditions, optimistic patients adapt better to stressful situations compared to pessimists, with positive repercussions on their quality of life. For example, in a sample of patients who underwent an aortic-coronary bypass, optimism was significantly and positively associated with quality of life in the six months following the operation [39]. The optimistic patients in fact presented a more rapid clinical improvement during the period of hospitalization and a quicker return to daily routine after discharge from hospital. Analogous results are reported in samples of patients with other pathologies. In patients affected with epilepsy, Pais-Ribeiro et al. [40] found that optimists showed an improved perception of their physical and mental state of health and reported higher quality of life compared to pessimists. Kung et al. [41] examined the relation between optimism-pessimism and quality of life in patients with cancer of the neck, head or thyroid. In all the subjects, optimism was associated with better quality of life in both the scales of the physical and_mental components of the MMPI (Minnesota Multiphasic Personality Inventory) [42], in six of the eight subscales of the SF-12 (12-item Short Form Health Survey) [43] and of the SF-36 (36-item Short Form Health Survey) [44].

Lastly, in women with breast cancer, optimism was associated with better quality of life in terms of emotional, functional and socio-familial well-being [45].

Many studies have outlined the importance on quality of life of an individual's capacity to adapt and modify his/her own objectives according to different situations [32, 34]. It is possible to avoid or reduce the negative psychological and physical repercussions consequent to the non-achievement of a goal (for example, becoming ill despite constant efforts to stay healthy) through a process of adaptive self-regulation targeted at disengaging oneself from an unrealizable goal and concentrating efforts instead on more attainable objectives. In fact this form of release from a commitment is adaptive because it averts the patient from the emotionally negative consequences of repeated failures, while re-directing the objectives gives back meaning and a sense of purpose to life. Individuals who succeed in this present better quality of life and better physical health compared to those who have greater difficulty in renouncing their unattainable goals. Moreover, they are more optimistic towards their future because they are able to manage difficulties more efficiently as well as to identify new aims in life.

\section{OPTIMISM, HEALTH LIFESTYLE AND RISK PER- CEPTION}

One way in which optimism may significantly influence physical well-being is through promotion of a healthy lifestyle. In fact, it is thought that optimism facilitates adaptive behaviours and cognitive responses that consent negative information to be elaborated more efficiently and that are associated with greater flexibility and problem-solving capacity [3]. These coping strategies are in turn predictive of behaviours targeted at avoiding, and if necessary facing positively, health problems $[46,47]$.

Several studies have analysed the correlations between optimism and healthy behaviours. In particular Steptoe et al. [48] in a sample of males and females aged between $65-80$ years found that optimism was correlated with healthy behaviours such as abstaining from smoking, moderate consumption of alcohol, the habit of walking briskly and regular physical activity, regardless of demographical factors, current psycho-physical conditions and body mass.

A recent cohort study which examined 545 males aged between $64-84$ for fifteen years revealed a significant inverse relation between dispositional optimism and death for cardio-vascular diseases, with a reduction of $50 \%$ of the risk of cardio-vascular death in the optimistic individuals [49].

Numerous researches have investigated the relation between risk perception and unrealistic optimism that leads to involvement in risky situations. Unrealistically optimistic subjects tend to perceive themselves as being less at risk compared to pessimists, as far as questions of health are concerned, and furthermore believe themselves more capable of 
preventing such problems from happening [4]. For example, comparing groups of students with a marked disposition towards risky behaviour and students having a low tendency to get involved in such behaviour, Todesco and Hillman [50] found that both groups assessed the possibility of damaging consequences of a given situation, but the first group was at variance for the fact that these students perceived themselves as invulnerable.

Smokers represent an important field in the study of the relation between unrealistic optimism and perception of risk for the health. These subjects consider themselves to be less at risk than others for developing illnesses associated with smoking which has been interpreted as a form of irrationality or rather, as an expression of optimistic bias. McKenna et al. [51] illustrated that smokers, while considering themselves to have a greater risk of contracting pathologies linked to smoking compared to non-smokers, nonetheless perceived such a risk as inferior when compared to the average number of smokers (optimistic bias). More recent studies have indicated that smokers have a significantly lower perception of risk in comparison with non-smokers [52]. By way of confirmation of these data, it was observed that smokers with unrealistic optimism (that is, those who perceived their own risk as lower than the effective risk) tended to believe that smoking only for a few years they would not incur any risk of lung cancer and that developing lung cancer depends solely on genetic predisposition [53].

Furthermore, unrealistic optimists barely considered the hypothesis of giving up smoking in order to reduce the risk of cancer.

\section{CONCLUSIONS}

Optimism is a tendency to expect good things in the future. From the literature here reviewed, it is apparent that optimism is a mental attitude that heavily influences physical and mental health, as well as coping with everyday social and working life. Through an adaptive management of personal goals and development and by using active coping tactics, optimists are significantly more successful than pessimists in aversive events and when important life-goals are impaired.

Clinics should develop an application form of optimism concept in Applied Psychology and in Psychotherapy. As a matter of fact, application form of optimism concept should be integrated in treatments and prevention programs respectively in mental and physical health, to improve well-being.

\section{AUTHORS' CONTRIBUTIONS}

The authors conceived the manuscript and drafted it. All authors read and approved the final manuscript.

\section{REFERENCES}

[1] Scheier MF, Carver CS. Optimism, coping, and health: assessment and implications of generalized outcome expectancies. Health Psychol 1985; 4(3): 219-47.

[2] Peterson C, Seligman ME. Explanatory style and illness. J Pers 1987; 55(2): 237-65.

[3] Aspinwall LG, Richter L, Hoffman RR. Understanding how optimism works: an examination of optimists' adaptive moderation of belief and behaviour. In: Optimism and pessimism. Chang EC, Ed. Washington: American Psychological Association 2001; pp. 21738.
[4] Peterson C, De Avila ME. Optimistic explanatory style and the perception of health problems. J Clin Psychol 1995; 51(1): 128-32.

[5] Weinstein ND. Unrealistic optimism about future life events. J Pers Soc Psychol 1980; 39(5): 806-20.

[6] Weinstein ND. Why it won't happen to me: perception of risk factors and susceptibility. Health Psychol 1984; 3(5): 431-57.

[7] Chang EC, Sanna LJ. Optimism, pessimism, and positive and negative affectivity in middle-aged adults: a test of a cognitive-affective model of psychological adjustment. Psychol Aging 2001; 16(3): 524-31.

[8] Hart SL, Vella L, Mohr DC. Relationships among depressive symptoms, benefit-finding, optimism, and positive affect in multiple sclerosis patients after psychotherapy for depression. Health Psychol 2008; 27(2): 230-8.

[9] Hirsch JK, Conner KR, Duberstein PR. Optimism and suicide ideation among young adult college students. Arch Suicide Res 2007; 11(2): 177-85.

[10] Hirsch JK, Conner KR. Dispositional and explanatory style optimism as potential moderators of the relationship between hopelessness and suicidal ideation. Suicide Life Threat Behav 2006; 36(6): 661-9.

[11] Van der Velden PG, Kleber RJ, Fournier M, Grievink L, Drogendijk A, Gersons BP. The association between dispositional optimism and mental health problems among disaster victims and a comparison group: a prospective study. J Affect Disord 2007; 102(1-3): 35-45.

[12] Steele A, Wade TD. The contribution of optimism and quality of life to depression in an acute coronary syndrome population. Eur J Cardiovasc Nurs 2004; 3(3): 231-7.

[13] Giltay EJ, Kamphuis MH, Kalmijn S, Zitman FG, Kromhout D. Dispositional optimism and the risk of cardiovascular death: the Zutphen Elderly Study. Arch Intern Med 2006; 166(4): 431-6.

[14] Basoglu M, Salcioglu E, Livanou M, Kalender D, Acar G. Singlesession behavioral treatment of earthquake-related Post-traumatic Stress Disorder: a randomized waiting list controlled trial. J Trauma Stress 2005; 8(1): 1-11.

[15] Martínez-Correa A, Reyes del Paso GA, García-León A, GonzálezJareño MI. Relationship between dispositional optimism/pessimism and stress coping strategies. Psicothema 2006; 18(1): 66-72.

[16] Giltay EJ, Geleijnse JM, Zitman FG, Hoekstra T, Schouten EG. Dispositional optimism and all-cause and cardiovascular mortality in a prospective cohort of elderly dutch men and women. Arch Gen Psychiatry 2004; 61(11): 1126-35.

[17] Matthews KA, Räikkönen K, Sutton-Tyrrell K, Kuller LH. Optimistic attitudes protect against progression of carotid atherosclerosis in healthy middle-aged women. Psychosom Med 2004; 66(5): 640-4.

[18] Schulz R, Bookwala J, Knapp JE, Scheier MF, Williamson GM. Pessimism, age and cancer mortality. Psychol Aging 1996; 11(2): 304-9.

[19] Allison PJ, Guichard C, Fung K, Gilain L. Dispositional optimism predicts survival status 1 year after diagnosis in head and neck cancer patients. J Clin Oncol 2003; 21(3): 543-548.

[20] Ironson G, Balbin E, Stuetzle R, et al. Dispositional optimism and the mechanisms by which it predicts slower disease progression in AIDS: proactive behavior, avoidant coping, and depression. Int J Behav Med 2005; 12(2): 86-97.

[21] Schofield P, Ball D, Smith JG, et al. Optimism and survival in lung cancer patients. Cancer 2004; 100(6): 1276-82.

[22] Tomakowsky J, Lumley MA, Markowitz N, Frank C. Optimistic explanatory style and dispositional optimism in HIV-infected men. J Psychosom Res 2001; 51(4): 577-87.

[23] Milam JE, Richardson JL, Marks G, Kemper CA, McCutchan AJ. The roles of dispositional optimism and pessimism in HIV disease progression. Psychol Health 2004; 19: 167-81.

[24] Segerstrom SC: Optimism and immunity: do positive thoughts always lead to positive effects? Brain Behav Immun 2005; 19(3): 195-200.

[25] Segerstrom SC. How does optimism suppress immunity? Evaluation of three affective pathways. Health Psychol 2006; 25(5): 6537.

[26] Lazarus RS, Opton EM. A study of psychological stress: a summary of theoretical formulations and experimental findings. In: Spielberger CD. Ed. Anxiety and Behavior. New York: Academic Press 1966; pp. 225-62. 
[27] Scheier MF, Weintraub JK, Carver CS. Coping with stress: divergent strategies of optimists and pessimists. J Pers Soc Psychol 1986; 51(6): 1257-64.

[28] Nes LS, Segerstrom SC. Dispositional optimism and coping: a meta-analytic review. Pers Soc Psychol Rev 2006; 10(3): 235-51.

[29] Billingsley KD, Waehler CA, Hardin SI. Stability of optimism and choice of coping strategy. Percept Mot Skills 1993; 76(1): 91-7.

[30] Boman P, Yates GC. Optimism, hostility, and adjustment in the first year of high school. Br J Educ Psychol 2001; 71(3): 401-411.

[31] Strutton D, Lumpkin J. Relationship between optimism and coping strategies in the work environment. Psychol Rep 1992; 71(3): 1179-86.

[32] Rasmussen HN, Wrosch C, Scheier MF, Carver CS. Self-regulation processes and health: the importance of optimism and goal adjustment. J Personal Disord 2006; 74(6): 1721-48.

[33] Scheier MF, Carver CS, Bridges MW. Distinguishing optimism from neuroticism (and trait anxiety, self-mastery, and self-esteem): a reevaluation of the life orientation test. J Pers Soc Psychol 1994; 67(6): 1063-78.

[34] Wrosch C, Scheier MF. Personality and quality of life: the importance of optimism and goal adjustment. Qual Life Res 2003; 12(1): 59-72.

[35] Schou I, Ekeberg Ø, Ruland CM. The mediating role of appraisal and coping in the relationship between optimism-pessimism and quality of life. Psychooncology 2005; 14(9): 718-27.

[36] Cummins RA. Comprehensive quality of life scale: intellectual disability, $3^{\text {rd }}$ ed, revised. Melbourne: Deakin University, Psychology Research Centre 1992.

[37] Scheier MF, Carver CS. Effects of optimism on psychological and physical well-being: theoretical overview and empirical update. Cogn Ther Res 1992; 16: 201-28.

[38] Scheier MF, Carver CS. Self-regulatory processes and responses to health threats: effects of optimism on well-being. In: Suls J, Wallston KA, Eds. Social psychological foundations of health and illness. Oxford: Blackwell 2003; pp. 395-428.

[39] Scheier MF, Matthews KA, Owens JF, et al. Dispositional optimism and recovery from coronary artery bypass surgery: the beneficial effects on physical and psychological well-being. J Pers Soc Psychol 1989; 57(6): 1024-40.
[40] Pais-Ribeiro J, Da Silva AM, Meneses RF, Falco C. Relationship between optimism, disease variables, and health perception and quality of life in individuals with epilepsy. Epilepsy Behav 2007; 11(1): 33-8.

[41] Kung S, Rummans TA, Colligan RC, et al. Association of optimism-pessimism with quality of life in patients with head and neck and thyroid cancers. Mayo Clin Proc 2006; 81(12): 1545-52.

[42] Hathaway SR, McKinley JC. The MMPI Manual. New York: Psychological Corporation 1940.

[43] Ware JE Jr, Kosinski M, Keller SD. A 12-Item Short-Form Health Survey: construction of scales and preliminary tests of reliability and validity. Med Care 1996; 34(3): 220-33.

[44] Ware JE Jr. SF-36 Health survey: manual and interpretation guide. Boston: Nimrod Press 1993.

[45] Friedman LC, Kalidas M, Elledge R, et al. Optimism, social support and psychosocial functioning among women with breast cancer. Psychooncology 2006; 15(7): 595-603.

[46] Braverman MT. Research on resilience and its implications for tobacco prevention. Nicotine Tob Res 1999; 1(1): 67-72.

[47] Cooper ML, Russell M, Skinner JB, Frone MR, Mudar P. Stress and alcohol use: moderating effects of gender, coping, and alcohol expectancies. J Abnorm Psychol 1992; 101(1): 139-52.

[48] Steptoe A, Wright C, Kunz-Ebrecht SR, Iliffe S: dispositional optimism and health behavior in community-dwelling people: associations with healthy ageing. Br J Health Psychol 2006; 11(1): 71-84.

[49] Giltay EJ, Geleijnse JM, Zitman FG, Buijsse, Kromhout D. Lifestyle and dietary correlates of dispositional optimism in men: the Zutphen Elderly Study. J Psychosom Res 2007; 63(5): 483-90.

[50] Todesco P, Hillman SB. Risk perception: unrealistic optimism or realistic expectancy. Psychol Rep 1999; 84(3): 731-8.

[51] McKenna FP, Warburton DM, Winwood M. Exploring the limits of optimism: the case of smokers' decision making. Br J Psychol 1993; 84(3): 389-94.

[52] Weinstein ND, Marcus SE, Moser RP. Smokers' unrealistic optimism about their risk. Tob Control 2005; 14(1): 55-9.

[53] Dillard AJ, McCaul KD, Klein WM. Unrealistic optimism in smokers: implications for smoking myth endorsement and selfprotective motivation. J Health Commun 2006; 11(1): 93-102.

Received: October 14, 2009

Revised: February 28, 2010

Accepted: February 28, 2010

(c) Conversano et al.; Licensee Bentham Open .

This is an open access article licensed under the terms of the Creative Commons Attribution Non-Commercial License (http: //creativecommons.org/licenses/by-nc/3.0/) which permits unrestricted, non-commercial use, distribution and reproduction in any medium, provided the work is properly cited. 